\title{
Research on Independent Innovation Ability from the Perspective of Organization: Interactive Effect of Technological Innovation Performance and Knowledge Integration Ability
}

\author{
Dongpu Li, Hai Hu \\ School of Business, Nanjing Normal University, Nanjing, China \\ Email: jadeldp1992@163.com
}

How to cite this paper: $\mathrm{Li}, \mathrm{D} . \mathrm{P}$. and $\mathrm{Hu}$, H. (2018) Research on Independent Innovation Ability from the Perspective of Organization: Interactive Effect of Technological Innovation Performance and Knowledge Integration Ability. Journal of $\mathrm{Hu}$ man Resource and Sustainability Studies, 6 , 185-197.

https://doi.org/10.4236/jhrss.2018.62036

Received: May 21, 2018

Accepted: June 16, 2018

Published: June 19, 2018

Copyright $\odot 2018$ by authors and Scientific Research Publishing Inc. This work is licensed under the Creative Commons Attribution International License (CC BY 4.0).

http://creativecommons.org/licenses/by/4.0/

\begin{abstract}
The previous research on independent innovation ability has explored the impact of technological innovation performance on it, and lacked the common influence of knowledge integration ability and technological innovation performance on independent innovation ability. This paper introduces knowledge integration ability into independent innovation capability model to carry out empirical examination. The results verify the establishment of this model: There was a significant positive correlation between technological innovation performance and independent innovation capability, knowledge integration ability and independent innovation capability; there was a significant interactive effect between technological innovation performance and knowledge integration ability.
\end{abstract}

\section{Keywords}

Independent Innovation Ability, Technological Innovation Performance, Knowledge Integration Ability, Interactive Effect

\section{Introduction}

Innovation can input untiring motives and dynamism to the progress and development of the country and society. A basic unit of the country and society is the enterprise. To achieve the progress and development of society and further improve the nation's ability to innovate, the company must continuously improve producing and manufacturing processes, integrate various internal and 
external knowledge required by the company. In recent years, with the "innovation-driven development" strategy proposed, technological innovation has become a key for companies to obtain their own development and improve their own technology. Due to the high risk and complexity of technological innovation, the process of innovation is extremely prone to failure, resulting in low performance of their technological innovation. However, in order to adapt to the competition of economic globalization, maintain the competitive advantages of enterprises, and realize the stability and long-term development of enterprises, it is necessary to improve the technological innovation performance of enterprises. On the one hand, it can improve the technological level to improve the company's technological innovation capability; on the other hand, it is necessary to apply the technological research and achievements. In the era of knowledge economy, enterprises must not only focus on improving their own technological innovation performance, but also focus on integrating various internal and external knowledge required by the enterprise and putting knowledge integration in an important strategic position. Knowledge is a very important innovative resource and strategic resource in the process of independent innovation. Through the acquisition, utilization and innovation of all kinds of knowledge, the enterprise obtains the continuous competitive advantage in the complex market environment. Through the integration of various kinds of knowledge, the enterprise can form the unique knowledge system. It can make the enterprise find the opportunity of innovation and prepare for the independent innovation.

According to the relevant research at home and abroad, most scholars study the influence factors of independent innovation ability from the single angle of technological innovation performance or knowledge integration ability. Few scholars combine the two to explore their influence on independent innovation ability. This paper not only combines the two, but also explores the impact of the interaction between these two factors, and puts forward the influence model of the independent innovation ability from the organizational perspective.

\section{Literature Review and Research Hypothesis}

\subsection{Technological Innovation Performance (TI), Knowledge Integration Ability (KI), Independent Innovation Ability (II)}

Chiesa et al. (1996) believed that technological innovation referred to some of the technological activities that can be carried out in an enterprise, including providing some resources to the enterprise, making full use of the enterprise system and some technical tools [1]. Gao Jian first proposed the concept of TIP in China, that the enterprise's development and contribution to the enterprise in the process of technological innovation is TIP [2].

According to the theory of knowledge innovation, Nonaka pointed out that on the one hand knowledge integration was carried out between explicit knowledge and invisible knowledge, and on the other hand between organizations and individuals [3]. The study of Nonaka illustrates how knowledge is integrated and 
what the scope of integration is. Ren Hao, Deng Sanhong (2002) pointed out that knowledge integration is the process of assembling and integrating all kinds of knowledge inside and outside the enterprise by using some special and scientific means to form the unique knowledge system [4].

Leites (2006) believes that the process of enterprises' independent innovation is to mobilize enterprise resources and use all aspects of their ability to develop new products and services [5]. Senge (2002) thinks that it is a major feature of enterprises' independent innovation to acquire the unique technology of enterprises through technological R \& D [6]. The Chinese scholars, such as Yang Xiaoxi (2002) [7] and Huang Yi (2006) [8], believe that independent innovation is enterprises use all aspects of resources to break through their own technology and transform them into enterprise profits to achieve their own goals.

\subsection{Technological Innovation Performance to Independent Innovation Ability}

Grossman (1991) first proposed that technological innovation was an important factor affecting the independent innovation ability of an enterprise. At the same time, he pointed out that the technology innovation model of enterprise must be changed to improve the ability of independent innovation and to highlight its position in the enterprise [9]. According to the independent research and development theory, the research of Patrick and Hussler (2005) shows that the independent innovation ability has a significant positive correlation with the R \& $\mathrm{D}$ investment of the enterprises and the R \& D personnel, and the achievements of high-tech enterprises, local institutions and government are reflected directly by the innovation performance of technology [10]. The performance of technological innovation has certain influence on independent innovation ability. Relevant Chinese scholars have also confirmed that technological innovation has become an important factor affecting the independent innovation ability of enterprises. Fu Jiaji (1998) believed that independent innovation generally referred to the organization on the basis of its original knowledge and technological stock, by learning, absorbing and integrating external knowledge, producing new technology and new methods to achieve the goal [11]. On this basis, the following hypothesis is proposed:

H1: technological innovation performance has a significant positive impact on enterprise's independent innovation ability.

The enterprise core competence theory of C. K. Praharad and G. Hamel points out that the ability is not imitable, unique and applicable. Such ability will make the enterprise dominant in the competition. Enterprises produce and manufacture products with high uniqueness and practicability based on their own technological innovation ability. On the one hand, it improves the enterprise's competitive initiative in the complex market environment, on the other hand, improves the independent research and development ability of enterprises in the process of production and manufacture. At the same time, the innovation of the technology has also improved the producing process, which has an im- 
portant influence on improving the production and manufacturing capacity of the enterprise and improving the production efficiency. Therefore, this paper puts forward the following hypothesis:

H1a: technological innovation ability has a significant positive impact on independent R \& D capability.

H1b: technological innovation ability has a significant positive impact on manufacturing capability.

Schumpeter's innovation theory points out that innovation includes the production of a new product in five aspects. The production of a new product here is through technological innovation, the enterprise develops a new product independently and uses a new production method to improve the production of the enterprise through technological innovation. The manufacturing process can further improve the manufacturing capability of enterprises. The enterprise is through the application of its technological innovation to produce new product development and improve the production process. Therefore, the technological innovation output of enterprises has a positive impact on improving their independent R \& D capability and manufacturing capacity. Therefore, this article puts forward the following hypothesis:

H1c: technological innovation output has a significant positive impact on independent R \& D capability.

H1d: technological innovation output has a significant positive impact on manufacturing capacity.

\subsection{Knowledge Integration Ability to Independent Innovation Ability}

Knowledge assets have become one of the most important assets of enterprises in today's complex and changeable market environment. By integrating the internal and external knowledge, the enterprise summarizes the explicit knowledge and tacit knowledge in each link of $\mathrm{R} \& \mathrm{D}$, production and sales, and realizes the sharing of knowledge, thus transforming the enterprise knowledge into productivity. At the same time, the process of knowledge integration is also an innovative management process. Through knowledge integration to achieve knowledge innovation, $\mathrm{R} \& \mathrm{D}$ team and technical personnel in the process of $\mathrm{R} \& \mathrm{D}$ and production applying the integrated knowledge to improve the enterprise's ability of independent innovation. Grant (1996) divided knowledge into four levels. At the same time, he believed that knowledge integration was expanded to form enterprise knowledge innovation on the basis of this scope [12]. For the first time, the research shows that the integration of various kinds of knowledge will affect the knowledge innovation. The effect of knowledge innovation on the R \& $\mathrm{D}$ and production of the enterprise will be transformed into the development and application of new products and new technologies. From the perspective of enterprise independent innovation theory, Raghu Garud and Praveen R. Nayyar [13] believe that the improvement of enterprise innovation ability depends on the integration and accumulation of related knowledge, and the reason for the 
occurrence of enterprise innovation behavior is precisely because of this. Their research shows that enterprises can effectively improve their innovation capability by integrating and summarizing relevant knowledge. Therefore, this article puts forward the following hypothesis:

$\mathrm{H} 2$ : knowledge integration ability has a significant positive impact on independent innovation ability.

The theory of knowledge integration holds that knowledge integration refers to the integration of all kinds of knowledge that will guide the production and practice of enterprises, so that the integrated knowledge is systematized and standardized, and has strong flexibility and adaptability, thus forming a dynamic process of the core knowledge system and system of the enterprise. The ability of systematization in knowledge integration refers to the ability of employees to use enterprise information systems on the basis of work arrangements and regulations, or in accordance with the degree of standardization. In the process of knowledge integration, systematization mainly embodies the integration of explicit knowledge inside and outside the enterprise, and forms a set of standardized knowledge base and workflow through integration, which greatly improves the efficiency of employees' use of enterprise knowledge. The employees use the standardized knowledge base and the hidden knowledge accumulated by their own working experience to form their own unique knowledge. By using it in the development of new products and new technologies, it greatly improves the ability of independent research and development of enterprises, and also greatly raises the success rate of high and new products and new technologies. And it can further improve the manufacturing capacity and efficiency of enterprises. Therefore, this paper puts forward the following hypothesis:

H2a: systematization capability has a significant positive impact on independent R \& D capability.

H2b: systematization capability has a significant positive impact on manufacturing capability.

The key to enterprise's knowledge integration is to maximize the implicit knowledge within the enterprise, so as to realize the transmission and mine of its value inside the enterprise. According to knowledge sharing theory, the transmission of knowledge requires collaboration and communication. Therefore, if we want to transform the tacit knowledge of enterprises, we need close cooperation and communication between employees. The ability of collaboration refers to the ability of employees and employees, departments and departments to achieve their established goals through communication and collaboration. Through cooperation and communication between employees, the knowledge of individual employees is spread, and the knowledge stock of individual employees is improved. Then, the ability of employees to develop new products and technologies with integrated knowledge is improved, and the ability of independent research and development is improved. The close cooperation and communication has greatly improved the efficiency of enterprises in the production process, thus improved the manufacturing capacity of enterprises. Therefore, this paper puts 
forward the following hypothesis:

$\mathrm{H} 2 \mathrm{c}$ : collaborative capability has a significant positive impact on independent R \& D capability.

H2d: collaborative capability has a significant positive impact on manufacturing capability.

The organizational social atmosphere theory proposed by Christopher J. Collins in 2006 pointed out that in order to achieve a good enterprise culture and promote the transformation and absorption of knowledge within the organization, enterprises should create a kind of organizational atmosphere of sharing, mutual helping and cooperation in the process of human resource practice. Socialization capability refers to the ability of employees to identify with enterprises and have a certain sense of belonging to enterprises by creating strong corporate culture. The corporate culture that is good at sharing and cooperating within an enterprise will affect employees' initiative to accept new knowledge and share their work experience. Under the guidance of the organizational atmosphere of enterprise innovation culture, employees will improve their knowledge by mutual cooperation and communication. At the same time, the integrated knowledge can be used to improve the current work content and means, and ultimately improve the independent research and development ability and production capacity of the enterprise. Therefore, this paper puts forward the following hypothesis:

H2e: socialization capability has a significant positive impact on independent R \& D capability.

H2f: socialization capability has a significant positive impact on manufacturing capability.

\subsection{Interactive Effect of Technological Innovation Performance and Knowledge Integration Ability}

In the process of enterprise independent innovation, technological innovation and knowledge integration are indispensable parts of this process. Ians and West put forward in 1997 that in order to adapt to the increasingly competitive market environment, the efficiency of R \& D and technical integration of enterprises are very important for enterprises to gain competitive advantage [14]. This shows that technological innovation is closely related to knowledge integration. In 1999, Hoopes and Postrel analyzed the failure of enterprises due to the lack of knowledge integration. The results of the research directly demonstrated the role of knowledge integration in promoting the transformation of technology innovation to independent innovation [15]. Knowledge integration can form an enterprise's unique knowledge system, and realize the transformation of innovation output to improve the innovation ability of the enterprise through using knowledge. Katila's research in 2002 proved this [16]. Chinese scholars have also demonstrated the interaction between technological innovation and knowledge integration from different perspectives. In 2013, Wang Ling and Shen Enping, concluded that knowledge integration could accelerate the process of enterprise 
innovation through the analysis of the factors influencing the transfer of enterprises' technology [17]. When enterprises realize independent innovation through knowledge integration, the level of enterprise technological innovation requires the integration of knowledge to the technical level. The integrated knowledge is not arbitrary, but for the enterprise's technology research and development and innovation service. Therefore, based on the study of scholars at home and abroad, the following assumptions are made:

$\mathrm{H} 3$ : there is interaction effect between technological innovation performance and knowledge integration capability.

\subsection{The Proposal of the Model}

Therefore, based on the research of scholars, this paper puts forward the influence model of independent innovation capability from the perspective of organization (Figure 1).

\section{Research Methods}

\subsection{Research Object}

In this paper, according to the research of Knut et al. and Volberda, the questionnaire survey and online questionnaire are carried out mainly by the technical R \& D personnel and middle managers of the enterprises. A total of 300 questionnaires were distributed and 281 were recovered, of which 243 were valid questionnaires, with an effective recovery rate of $86.48 \%$. Among the 243 valid questionnaires, the information industry accounted for $25.9 \%$, the bio medicine and water conservancy and hydropower accounted for $18.5 \%$, the clothing textile and financial industry accounted for $10.29 \%$, the petrochemical industry accounted for $11.11 \%$, and the other industries accounted for $5.41 \%$; the enterprises that were established for more than 20 years accounted for $14.98 \%, 10$ to 20 years accounted for $28.44 \%$, 5 year to 10 years accounted for $18.5 \%$ years. The accounts accounted for $20.35 \%$; enterprises with enterprises under 100 persons accounted for $28.44 \%, 100$ to 500 enterprises accounted for $35.62 \%, 500-1000$ enterprises accounted for $25.82 \%$, and more than 1000 enterprises accounted for $10.12 \%$. This sample is basically consistent with reality and has representativeness (Table 1).

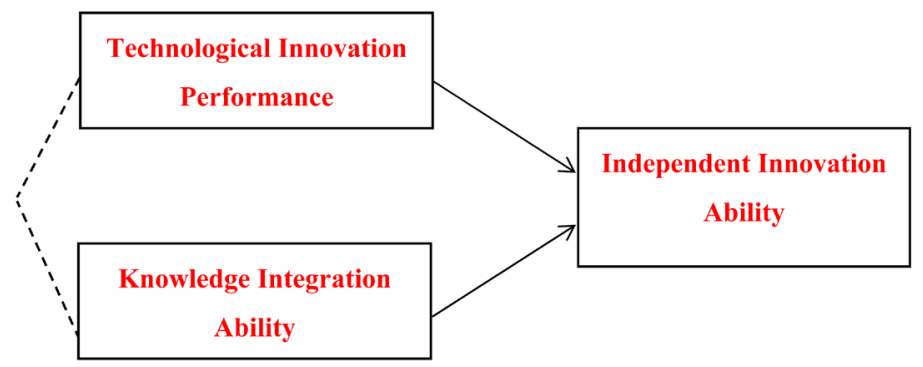

Figure 1. The influence model of independent innovation ability from the perspective of organization. 
Table 1. Basic distribution of questionnaire $(\mathrm{N}=243)$.

\begin{tabular}{cccc}
\hline Index & Industry category & Enterprise scale & Enterprise establishment life \\
\hline Petrochemicals & $11.11 \%$ & & \\
Biomedicine & $18.5 \%$ & & \\
Information industry & $25.9 \%$ & & \\
Hydropower & $18.5 \%$ & & \\
Garment and textile & $10.29 \%$ & & \\
Finance & $10.29 \%$ & $28.44 \%$ & \\
Other industry & $5.41 \%$ & $35.62 \%$ & $20.35 \%$ \\
$\mathbf{1 0 0}$ or less & & $25.82 \%$ & $36.23 \%$ \\
$\mathbf{1 0 0}$ - $\mathbf{5 0 0}$ & & $10.12 \%$ & $28.44 \%$ \\
$\mathbf{5 0 0}-\mathbf{1 0 0 0}$ & & & $14.98 \%$ \\
$\mathbf{1 0 0 0}$ or more & & & \\
$\mathbf{5}$ years or less & & & \\
$\mathbf{5}-\mathbf{1 0}$ years & & & \\
$\mathbf{1 0}-\mathbf{2 0}$ years & & & \\
$\mathbf{2 0}$ years or more & & & \\
\hline
\end{tabular}

\subsection{Research Tools}

In this paper, by combing the literature at home and abroad, the scale of each variable is determined. The Likert 7 scale is used in all the scales in the study, from "very disapproval" to "very agreeing".

Technical innovation performance. Using Knut et al. (2001) and high construction (2004) scale, it is divided into 2 dimensions to measure the technological innovation ability and technological innovation output, each dimension contains 4 items.

Knowledge integration ability. According to the scale of Volberda, Kogut, Zander and Teece, it is divided into three dimensions, namely, systematization, collaboration and socialization, and each dimension contains 4 items [18].

Independent innovation ability. According to the survey of enterprises with innovative ability by the Chinese Enterprise Evaluation Association, it includes two dimensions of independent R \& D capacity and production capacity, and each dimension contains 4 items.

Control variables. Because of the different technical nature between different industries, and the different scale of enterprises and the different years of establishment determine the different degree of independent innovation of enterprises, so the control variables select industry category, enterprise scale and enterprise establishment life.

\section{Data Analysis and Results}

\subsection{Confirmatory Factor Analysis and Reliability Test}

The results show that the Cronbach's alpha value of the technical innovation 
performance is 0.858 , the Cronbach's a value of the knowledge integration ability is 0.919 , the Cronbach's alpha of the independent innovation ability is 0.930 , indicating that the collected data is credible. In order to test the structure validity of the questionnaire, the KMO values of each variable are measured. The results show that the KMO values of technical innovation performance, knowledge integration ability and independent innovation ability are $0.789,0.873$ and 0.825 respectively, and are suitable for factor analysis. The factor is extracted by the eigenvalue greater than 1, and the factor load matrix is rotated with the Varimax orthogonal rotation method. The results show that technological innovation performance formed 2 factors, knowledge integration ability formed 3 factors, independent innovation ability formed 2 factors, and the cumulative variance contribution rate is $72.168 \%, 77.097 \%$ and $83.664 \%$ respectively. Each variable has been found. The corresponding factor and factor load coefficient are all greater than 0.5 and less than 0.95 , which shows that the scale has good convergent validity. At the same time, all indexes in Table 2 have reached a good standard, indicating that the fitting degree of the model and data is good.

\subsection{Analysis of the Main Effect}

In this paper, multiple regression models are used to study the effects of variables on independent innovation capability and their interactive effects.

$\mathrm{II}=a_{0}+a_{1} \mathrm{TI}+a_{2} \mathrm{KI}+a_{3}$ TIKI $+a_{4}$ Year $+a_{5}$ Industry $+a_{6}$ Scale $+\varepsilon_{0}$

TIKI represents the interactive terms of two variables, $a_{i}$ is the regression coefficient, $a_{0}$ is constant, and $\varepsilon_{0}$ is the error term. The statistical software is used to process the collected data, and the linear regression analysis of the variables and their dimensions is carried out respectively. The modified $\mathrm{R}^{2}$ and the regression coefficient of the hypothesis are obtained.

According to the results of Table 3, the effect of technological innovation performance on independent innovation ability is significant at the significant level of 0.05 , and the effect of knowledge integration ability on independent innovation ability is significant. Therefore, it is assumed that $\mathrm{H} 1$ and $\mathrm{H} 2$ are verified. The regression equation shows that all the coefficients have reached a significant degree $(p<0.05)$, and the modified $\mathrm{R}^{2}$ value of the model equation is 0.426 , indicating that the equation has a certain explanatory power.

Model 2 represents the influence of technological innovation performance and knowledge integration capability on the independent R \& D capability of enterprises. Table 3 shows that the two dimensions of technological innovation performance are significantly positively related to the independent R \& D capability of the enterprise. In the significant level of 0.05 , the technological innovation

Table 2. Suitability index and numerical value of confirmatory factor analysis model.

\begin{tabular}{cccccccc}
\hline Index & $\chi^{2} / \mathrm{df}$ & GFI & NFI & IFI & CFI & RFI & RMSEA \\
\hline Model value & 1.845 & 0.901 & 0.911 & 0.974 & 0.932 & 0.905 & 0.078 \\
Reference value & $<3.000$ & $>0.900$ & $>0.900$ & $>0.900$ & $>0.900$ & $>0.900$ & $<0.080$ \\
\hline
\end{tabular}


Table 3. Correlation analysis of the main variables $(\mathrm{N}=243)$.

\begin{tabular}{ccccc}
\hline & Model 1 & Model 2 & Model 3 & Model 4 \\
\hline Industry & $0.019(0.579)$ & $0.048(0.218)$ & $0.008(0.804)$ & $0.031(0.374)$ \\
Year & $0.231^{* *}(0.003)$ & $0.447^{* *}(0.023)$ & $0.294^{* *}(0.031)$ & $0.221^{* *}(0.005)$ \\
Scale & $-0.212^{* *}(0.004)$ & $-0.302^{* *}(0.011)$ & $-0.460^{* *}(0.022)$ & $-0.250^{* *}(0.001)$ \\
TI & $0.558^{* *}(0.021)$ & & & $1.733^{* *}(0.009)$ \\
KI & $0.424^{* *}(0.002)$ & & & $1.616^{* *}(0.015)$ \\
TI1 & & $0.424^{* *}(0.013)$ & $0.120(0.083)$ & \\
TI2 & & $0.344^{* *}(0.027)$ & $0.445^{* *}(0.001)$ & \\
KI1 & & $0.385^{* *}(0.011)$ & $0.316^{* *}(0.014)$ & \\
KI2 & & $0.371^{* *}(0.001)$ & $0.234^{* *}(0.004)$ & \\
KI3 & & $0.574^{* *}(0.021)$ & $0.764^{* *}(0.018)$ & \\
KI×TI & & & & $0.211^{* *}(0.039)$ \\
AdjR & 0.426 & 0.420 & 0.591 & 0.431 \\
F value & 36.858 & 22.910 & 44.636 & 31.577 \\
\hline
\end{tabular}

Note: $* *$ indicates a significant level of $5 \%$. TI1 represents technological innovation capability, TI2 represents technological innovation output, KI1 represents systematization ability, KI2 represents cooperation ability, KI3 represents socialized ability, KITI represents the interaction of technical innovation performance and knowledge integration ability.

ability and technological innovation output have a significant positive correlation to the independent R \& D capability. Therefore, it is assumed that H1a and $\mathrm{H} 1 \mathrm{c}$ are verified. The three dimensions of knowledge integration ability have significant positive correlation to the independent R \& D capability of the enterprise. In the significant level of 0.05 , the effect of systematization, collaboration and socialized ability on independent research and development ability is significant. Therefore, it is assumed that $\mathrm{H} 2 \mathrm{a}, \mathrm{H} 2 \mathrm{c}$, and $\mathrm{H} 2 \mathrm{e}$ are verified. The regression equation shows that all the coefficients have reached a significant degree ( $p$ $<0.05$ ), and the modified $\mathrm{R}^{2}$ value of the model equation is 0.420 , indicating that the equation has a certain explanatory power.

Model 3 represents the influence of technological innovation performance and knowledge integration capability on the manufacturing capability of enterprises. It is shown in Table 3 that the $p$ value of technological innovation ability is 0.083 greater than 0.05 for production capacity, and it is not significant. The $p$ value of technological innovation output is less than 0.05 and has a significant positive correlation. Therefore, assuming that $\mathrm{H} 1 \mathrm{~b}$ cannot pass the test, $\mathrm{H} 1 \mathrm{~d}$ is verified. The three dimensions of knowledge integration ability are significantly positively related to the manufacturing capability of enterprises. Therefore, it is assumed that $\mathrm{H} 2 \mathrm{~b}, \mathrm{H} 2 \mathrm{~d}$, and $\mathrm{H} 2 \mathrm{f}$ are verified. The regression equation shows that in addition to the technological innovation ability, each coefficient has reached a significant degree $(p<0.05)$. The modified $\mathrm{R}^{2}$ value of the model is 0.591 , indicating that the equation has a certain explanatory power. 


\subsection{Analysis of Interactive Effect}

Model 4 represents the interaction between knowledge integration ability and technological innovation performance. It can be seen from Table 3 that, in the case of high knowledge integration, the positive impact of technological innovation performance on the independent innovation ability of enterprises is very significant, and the strength of enterprise knowledge integration can accelerate the transformation of enterprise innovation ability. Under the condition of low knowledge integration ability, technological innovation performance has a slow effect on enterprise's independent innovation capability. In the case of high technology innovation performance, the positive influence of knowledge integration ability on the independent innovation ability of enterprises is also obvious. By increasing the investment in technological innovation, it can effectively realize the transformation of knowledge integration into independent innovation. Under the condition of low technological innovation performance, knowledge integration has little influence on enterprise innovation capability. From the results of the model, interaction between technological innovation performance and knowledge integration ability is assumed, and $\mathrm{H} 3$ is verified. The modified $\mathrm{R}^{2}$ value of the model is 0.431 , indicating that the model has some explanatory power.

The results from Table 3 verify the establishment of this model: There was a significant positive correlation between technological innovation performance and independent innovation capability, knowledge integration ability and independent innovation capability; there was a significant interactive effect between technological innovation performance and knowledge integration ability.

\section{Research Conclusions}

In this study, the knowledge integration ability is introduced into the model of independent innovation ability to carry out an empirical test and explore the interaction of knowledge integration ability and technological innovation performance. The empirical results verify the establishment of this model: technological innovation performance and knowledge integration ability have a significant effect on the independent innovation ability at 0.05 significant level. There is a significant interaction between technological innovation performance and knowledge integration ability. Therefore, in guiding their management activities and production practices, enterprises should pay close attention to the input of enterprises in technological innovation and knowledge integration.

To improve their capability of independent innovation, enterprises should pay attention not only to technological input, but also to internal and external knowledge of enterprises. Most enterprises only pay attention to their input in technological innovation while guiding their own innovation, often ignored the key role of knowledge integration in the process of innovation. The results show that the impact of knowledge integration ability on enterprise innovation is also very obvious. Only better integrate various kinds of knowledge, can the enterprise guide the production and practice of the enterprise better. 
While guiding production and practice, enterprises should lay stress on building a strong corporate culture. Whether for the independent $\mathrm{R} \& \mathrm{D}$ capability of enterprises or the manufacturing capacity of enterprises, the impact of socialization ability on them is very obvious. Socialization capability requires enterprises to create strong corporate culture, so that the idea of innovation and knowledge integration can be recognized and supported by employees. This will enable employees to enhance the sense of belonging and identity to the enterprise, and ultimately guide the innovation practice of the enterprise and realize the progress of the enterprise.

In order to guide enterprises' innovation practice through integrating inside and outside knowledge, enterprises should rationally allocate three dimensions of knowledge integration capability. According to the research results, the influence of socialized ability on the independent innovation ability of enterprises is the biggest in the three dimensions, but the ability of enterprise knowledge integration can be improved without the only emphasis on the socialization ability. While building a strong enterprise culture, enterprises should also pay attention to the formation of standardized work processes and rules and regulations to improve the flexibility of enterprises. At the same time, cooperation between different departments should be enhanced to improve the cooperation level of different employees, so as to improve the efficiency of knowledge transfer.

In the process of enterprise's production and practice, the relationship between technological innovation and knowledge integration is closely related to the role of enterprises. On the one hand, the source of enterprises' independent innovation is technological innovation. Technological innovation can change the technical line of the enterprise and realize the uniqueness of the enterprise production and manufacture. The investment in the enterprise will certainly enhance the innovation ability of the enterprise. However, if enterprises do not integrate the knowledge needed by enterprises well, the cycle of enterprise innovation will be greatly extended. On the other hand, knowledge integration can make a good summary of the knowledge inside and outside the enterprise. Integrating all kinds of knowledge of the enterprise will make a good knowledge base for the realization of independent innovation. However, if the technical level of the enterprise is not systematic or lagging, there is no platform to be applied to the integrated knowledge of the enterprise, and even the waste of the enterprise resources. Therefore, in order to enhance the capability of independent innovation, we must give full play to the role of technological innovation and knowledge integration, and realize the effective combination of the two. This is of great significance for improving the efficiency of production and practice of enterprises, consolidating the core strengths of enterprises and realizing the long-term development of enterprises.

\section{References}

[1] Chiesa, D.M. and Shane, S. (1996) A Prisoner Dilemma Approach to Entrepreneur-Venture Capitalist Relationship. The Academy of Management Review, 22, 
$142-176$

[2] Gao, J., Wang, J.F. and Wei, P. (2004) Performance Indicators of Technological Innovation in Enterprises: Current Situation, Problems and New Conceptual Models. Research Management, 25, 125-131.

[3] Nonaka, L. (1994) A Dynamic Theory of Organizational Knowledge Creation. Organization Science, 5, 14-37. https://doi.org/10.1287/orsc.5.1.14

[4] Ren, H. and Deng, S.H. (2002) An Important Step in Knowledge Management-Knowledge Integration. Intelligence Science, 20, 650-653.

[5] Richard Leites, M. (2006) Breaking the Frontline of Innovation: Building an Interpretive Dimension of Innovation. Intellectual Property Agency, Beijing, 12-85.

[6] Senge, P. (2002) Fifth Practice. Sanlian Publishing House, Shanghai, 52-109.

[7] Yang, X.X. and Luo, L.Q. (2002) Technological Innovation in the 21 Century. Journal of South China University of Technology, No. 11, 2.

[8] Huang, Y. (2006) Analysis and Suggestions on the Pros and Cons of Independent Innovation and Imitative Innovation. China Science and Technology Information, No. 4,44 .

[9] Grossman, G.M. and Helpman, E. (1991) Quality Ladders and Product Cycles. Quarterly Journal of Economics, 106, 557-586. https://doi.org/10.2307/2937947

[10] Long, V. and Laestadius, S. (2016) An Indigenous Innovation: An Example from Mobile Communication Technology. Oxford Development Studies, 44, 113-133. https://doi.org/10.1080/13600818.2015.1111319

[11] Fu, J.J. (1998) Technological Innovation. Tsinghua University Press, Beijing, 97.

[12] Grant, R.M. (1996) Toward a Knowledge-Based Theory of the Firm. Strategic Management Journal, 17, 109-122. https://doi.org/10.1002/smj.4250171110

[13] Garud, R. and Nayyar, P.R. (1994) Transformative Capability: Continual Structuring by Intertemporal Technology Transfer. Strategic Management Journal, 1, 365-395. https://doi.org/10.1002/smj.4250150504

[14] Iansiti, M. and West, J. (1997) Technology Integration: Turning Great Research into Great Products. Harvard Business Review, 75, 69-79.

[15] Hoopes, D. and Postrel, S. (1999) Shared Knowledge, "Glitches" and Product Development Performance. Strategic Management Journal, 20, 837-865. https://doi.org/10.1002/(SICI)1097-0266(199909)20:9<837::AID-SMJ54>3.0.CO;2-I

[16] Katila, R. (2002) New Product Search over Time: Past Ideas in Their Prime. Academy of Management Journal, 45, 995-1010. https://doi.org/10.5465/3069326

[17] An, W.L. and Shen, E.P. (2013) The Influence of Organizational Learning on Technology Transfer Performance Based on Knowledge Integration Perspective. Enterprise Technology and Development, 343, 4-7.

[18] Volberda, H.W., De Boer, M. and Bosch, F.A.J. (1999) Management Organizational Knowledge Integration in the Emerging Multimedia Complex. Journal of Management Studies, 36, 379-398. https://doi.org/10.1111/1467-6486.00141 